\title{
Safety and efficacy of vaginal laser therapy for stress urinary incontinence: a meta-analysis
}

\author{
Yunong Wang ${ }^{1 \#}$, Chengli Wang ${ }^{2 \#}$, Feipeng Song ${ }^{2}$, Yaguang Zhou ${ }^{3}$, Yiguang Wang ${ }^{2} \wedge$ \\ ${ }^{1}$ Division of Dermatology, Beijing University of Chinese Medicine Third Affiliated Hospital, Beijing, China; ${ }^{2}$ Division of Urology, Dongfang \\ Hospital Beijing University of Chinese Medicine, Beijing, China; ${ }^{3}$ Division of Urology, Fangshan Hospital Beijing University of Chinese Medicine, \\ Beijing, China \\ Contributions: (I) Conception and design: Y Wang, C Wang, Y Wang; (II) Administrative support: Y Wang, C Wang; (III) Provision of study materials \\ or patients: Y Wang, Y Zhou, F Song; (IV) Collection and assembly of data: Y Wang, F Song; (V) Data analysis and interpretation: Y Wang, C Wang; \\ (VI) Manuscript writing: All authors; (VII) Final approval of manuscript: All authors. \\ \#These authors contributed equally to this work. \\ Correspondence to: Yiguang Wang. Division of Urology, Dongfang Hospital Beijing University of Chinese Medicine, No. 6 Fangxingyuan 1st Block, \\ Fengtai District, Beijing 100078, China. Email: wangyiguang666@163.com.
}

Backgroundz Laser therapy has recently been proposed as a novel treatment for stress urinary incontinence (SUI) due to offering several advantages. This study aimed to evaluate the safety and efficacy of laser treatment of SUI by a meta-analysis.

Methods: The systematic review registration number is INPLASY202080001. A comprehensive search to identify relevant studies was conducted using the PubMed, Embase, Cochrane Library, CNKI, VIP and Wanfang databases with a cutoff date of 1 November, 2020. Outcome measures were extracted based on subjective and objective indexes, including International Consultation on Incontinence Questionnaire-Short Form (ICIQ-UI-SF), Pelvic Organ Prolapse/Urinary Incontinence Sexual Questionnaire (PISQ-12), and objective measurements "1-hour pad test" (1-hour test under standardized conditions). Score changes before and after treatment were evaluated through meta-analysis. Subgroup analysis was performed according to geographic region, type of urinary incontinence (UI), severity of UI, age, and body mass index (BMI).

Results: Sixteen published clinical research studies, involving 899 patients with SUI, were included in this study. After laser treatment, the change in the ICIQ-SF score at 1, 2, and 6 months was $-5.49(95 \%$ CI: $-6.74--4.24 ; \mathrm{I} 2=91 \%, \mathrm{P}<0.01$ ), -4.97 (95\% CI: -6.24--3.71), and -5.48 (95\% CI: -6.15--4.81), respectively. The improvement in 1-hour pad weight test results at 1,3 , and 12 months post treatment was -5.59 (95\% CI: -6.93--4.25), -4.96 (95\% CI: -6.73--3.20), and -5.82 (95\% CI: -6.77--4.87), respectively. The PISQ-12 score increased by 5.39 (95\% CI: 1.20-9.58) following treatment. Subgroup analysis identified the type and severity of UI as the potential source of heterogeneity. Adverse effects were reported in 6 of the 16 trials and affected only a small number of patients. Most adverse events were mild or moderate and required no medical intervention or resolved in a few days.

Conclusions: Vaginal laser therapy appears to be a safe, effective, and minimally invasive treatment option for SUI that can be well tolerated by patients.

Keywords: Meta-analysis; stress urinary incontinence (SUI); laser; effectiveness

Submitted Jul 19, 2020. Accepted for publication Dec 03, 2020.

doi: 10.21037/apm-20-1440

View this article at: http://dx.doi.org/10.21037/apm-20-1440

^ ORCID: 0000-0001-5810-6965. 


\section{Intruoduction}

Stress urinary incontinence (SUI) is defined as an involuntary loss of urine during physical effort or exertion, or upon sneezing or coughing (1). The prevalence of SUI among middle-aged women is estimated to be $4-35 \%$ (2). Based on the Stamey incontinence scoring system, SUI is regularly categorized as mild (incontinence with coughing or straining), moderate (incontinence with change in position or walking), or severe (total incontinence at all times) (3). The condition can co-exist with other types of urinary incontinence (UI), or manifests as a symptom in other diseases. For instance, mixed urinary incontinence (MUI) is a combination of urge and SUI (4). Scilicet vulvovaginal atrophy, a genitourinary syndrome of menopause (GSM), can result in vaginal discomfort, which can include vagina vestibule and dryness, a burning sensation, vulvovaginal irritation, and irritative symptoms of the lower urinary tract, such as urinary frequency, urgency, incontinence, and recurrent urinary tract infections (5). SUI is related to pelvic floor dysfunction, which sees altered metabolism of the connective tissue, ultimately leading to insufficient support of the urogenital tract from depleted collagen production (6). Childbirth, trauma, or aging can result in decreased collagen content due to the destruction and reduced synthesis of collagen fibers in the pelvic floor (7).

Despite the availability of multiple treatments, such as pelvic floor muscle training, behavioral therapies, and surgery (8), there are limitations associated with these treatments. For instance, patients are unlikely to comply with a strict program of behavior modification and regular pelvic floor exercises (9). In addition, the adverse effects of transvaginal sling surgery may occur, including pain with sexual intercourse, pain on voiding, which leads to reluctance for patients to undergo surgical intervention (10). Therefore, vaginal laser therapy as a novel, safe, effective, well-tolerated, and minimally invasive treatment has become more widely used in outpatient settings. The efficacy of laser therapy for SUI treatment has been shown in several studies. Despite the promising results presented in these reports, their study populations were limited, which means the efficacy of this form of therapy has yet to be confirmed.

With this background in mind, in order to further explore the effectiveness and safety of vaginal laser therapy, a single-arm meta-analysis was conducted in our study. This research aims to strengthen the evidence base and offers a valuable guide for physicians and clinicians treating these patients, as well as a basis for future studies.
In this study, we consolidate previously published data, using subjective rating procedures International Consultation on Incontinence Questionnaire-Short Form (ICIQ-UI-SF) (11), Pelvic Organ Prolapse/Urinary Incontinence Sexual Questionnaire (PISQ-12) (12) and objective measurements "1-hour pad test" (1-hour test under standardized conditions) (13) to assess the improvement after laser therapy. In summary, our study was designed to evaluate the efficacy and safety of vaginal laser therapy for SUI. We present the following article in accordance with the PRISMA reporting checklist (available at http://dx.doi. org/10.21037/apm-20-1440).

\section{Methods}

\section{Search strategy}

The systematic review registration number is INPLASY202080001. The studies selected in this singlearm meta-analysis, were obtained from the PubMed, EMBASE, Cochrane Library databases, CNKI, VIP and Wanfang. The literature search was conducted to identify articles published from inception to November 1st, 2020, with no language restrictions, using the following Medical Subject Headings $(\mathrm{MeSH})$ terms and keywords: [Urinary Incontinence, Stress] AND [(lasers) OR laser]. The reference lists of eligible articles were also reviewed to identify studies that may have been omitted from the database searches. Figure 1 depicts the flow chart of the study selection.

\section{Selection criteria}

\section{Types of patients}

Women diagnosed with SUI based on the diagnostic criteria of the International Continence Society without any age and race limit. The exclusion criteria were as follows: patients with pelvic organ prolapse stage > II; literature reviews, comments, letters, pre-clinical, or basic research experiments; duplicated publications; or studies without sufficient data.

\section{Types of interventions}

Vaginal laser treatment including Erbium YAG laser and $\mathrm{CO}_{2}$ laser treatment.

\section{Types of control}

Patients were not randomized, and there was no control group. 


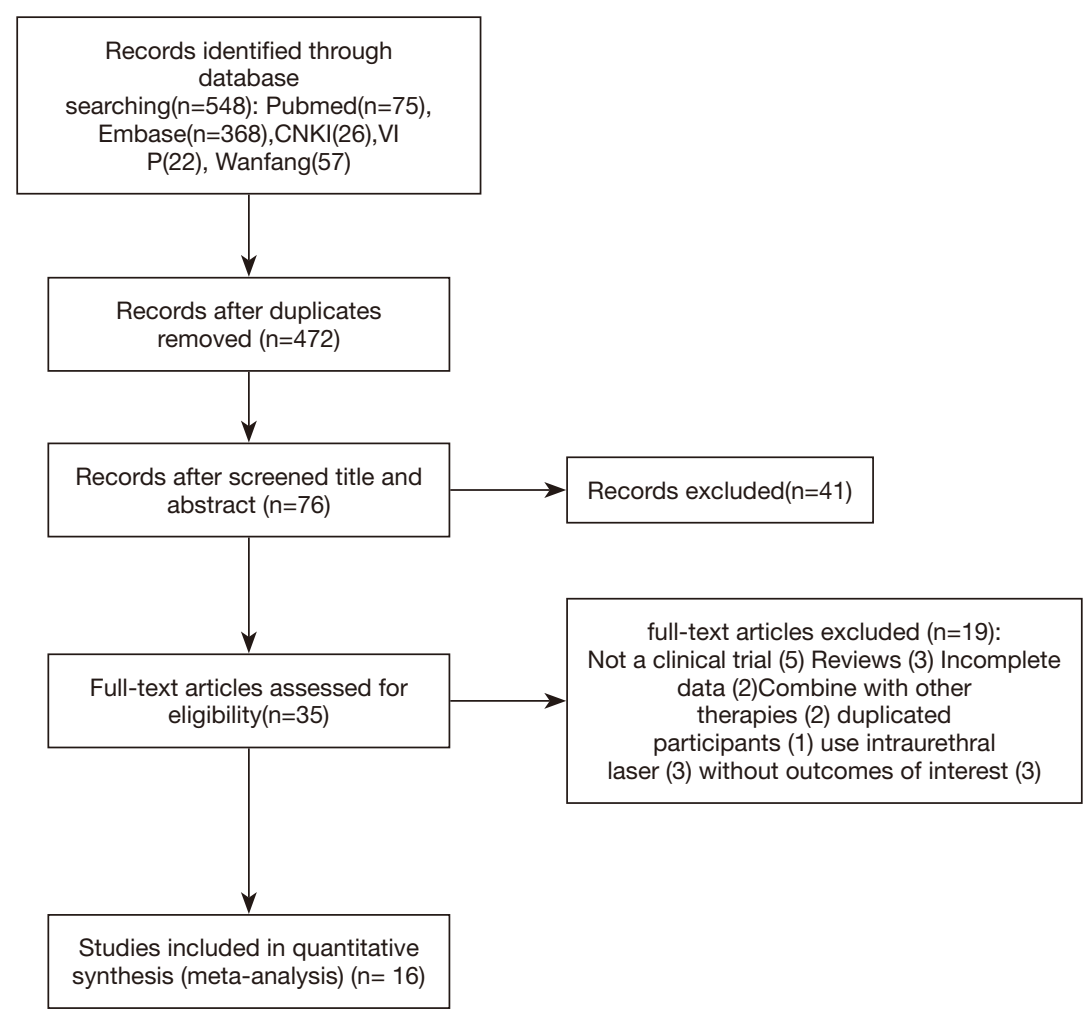

Figure 1 Preferred reporting items for systematic reviews and meta-analysis (PRISMA) flow diagram of the screening and selection of articles.

\section{Types of outcome measures}

The primary outcome was the change from baseline in the amount of ICIQ-SF scores. The secondary outcomes were the change scores of 1-hour pad test, frequency and nature of adverse events.

\section{Types of studies}

The inclusion criteria for the meta-analysis were as follows: prospective randomized or non-randomized clinical studies, retrospective clinical studies, or pilot studies.

\section{Data extraction}

Candidate articles were independently screened by two investigators by checking the titles and abstracts of the studies. The following information was extracted from the selected studies: first author; publication year; country of origin; patient sample size; type of research; mean age of patients; mean body mass index (BMI) of patients; type of laser; type of UI; therapy mode of laser; total number of sessions; follow-up duration; assessment parameters; and adverse reactions. Discrepancies between the investigators were resolved by consensus or the opinion of a third investigator was sought.

\section{Statistical analysis}

The methods of evaluations for this study were: ICIQ$\mathrm{SF}$ and the 1-hour pad test. Standard mean differences (SMDs) and 95\% confidence intervals (CIs) were expressed as the response indices of the efficacy of laser treatment. A $\mathrm{P} \leq 0.05$ was considered to be statistically significant. The heterogeneity of the included studies was assessed using $\mathrm{I}^{2}$. Studies with an $\mathrm{I}^{2}<25 \%$ were considered as not displaying heterogeneity. An $\mathrm{I}^{2}$ of $25-50 \%, 50-75 \%$, and $>75 \%$ was considered to represent low, moderate, and high heterogeneity, respectively. For cases of high heterogeneity, a subgroup analysis was performed to identify the sources of heterogeneity, based on geographic region, type of UI, severity of UI, age, and BMI. The meta-analysis was graphically represented by a forest plot, while the publication bias was represented by the inverted funnel 
plot. Due to insufficient data, heterogeneities attributed to menopausal status and the number of previous deliveries (parity) were not able to be determined.

\section{Results}

\section{Literature search}

Overall, 75 articles from PubMed, 368 articles from Embase, 26 articles from CNKI, 22 articles from VIP and 57 articles from Wanfang were originally selected for this meta-analysis. Further screening for duplicated documents reduced the number of articles to 472, before another 396 articles were excluded in accordance with the inclusion and exclusion criteria. Furthermore, 19 articles were reviewed and did not satisfy the eligibility criteria for this study, while 5 articles were not clinical trials. There were 3 reviews, 2 articles had incomplete data, 2 article combined laser treatment with other therapies, 1 article had duplicated participants, 3 used intraurethral laser, and 3 did not report outcomes of interest. Overall, 16 articles or abstracts were finally included in this single-arm meta-analysis. One of them was Chinese literature (14).

\section{Study characteristics}

A total of 899 cases were obtained from the 16 selected studies. The main characteristics of these studies are reported in Table 1.

The publication duration spanned across 5 years, from 2015 to 2020, with sample sizes ranging from 9-114 participants. Eight studies originated from Europe, 2 from South America and 2 from Asia, 1 from North America. The study types included 2 retrospective studies and 1 randomized controlled trial, with the others being prospective cohort studies. The only RCT we identified was a high-quality, low risk of bias study. Since the rest of selected studies were non-randomized controlled trails, which did not have a non-exposed group, the NOS scores ranged from 6 to 7. They all had detailed descriptions in the selection of patients and these findings. The summary of laser therapies and the correlating durations are reported in Table 2.

Two studies used external topic anesthesia, and 1 subject underwent local estrogen pre-treatment. Out of 3 studies that used $\mathrm{CO}_{2}$ lasers, the rest used SMOOTH mood of vaginal Erbium: YAG. The majority of therapies consisted of 2-3 treatment sessions with a 1-month interval between sessions, while other studies involved 1-5 treatment sessions. Follow-up time points were typically observed to be at 1,3 , and 6 months after the last treatment. Follow-up durations were up to 12 months or longer.

\section{Meta-analysis}

All selected studies showed data on the ICIQ-SF preintervention value, and 8 studies reported the ICIQ-SF value at 1 month post intervention. Five studies reported the value at 2 months and 9 studies reported the value at 6 months after intervention. (Kuszka et al. divided different degrees of SUI into two groups. These two groups represent two arms respectively in our study.) As shown in Figure 2, the 6-month ICIQ-SF values displayed no obvious asymmetry in the funnel plots, which suggested that no publication bias was present. A significant reduction in median ICIQ-SF scores between baseline and post-intervention reflects the efficacy of laser treatment. The difference in ICIQ-SF score was -5.49 (95\% CI: $\left.-6.74-4.24 ; \mathrm{I}^{2}=91 \%, \mathrm{P}<0.01\right)$ at 1 month, $-4.97(95 \%$ CI: $\left.-6.24-3.71 ; \mathrm{I}^{2}=85 \%, \mathrm{P}<0.01\right)$ at 3 months, and -5.48 (95\% CI: $\left.-6.15--4.81 ; \mathrm{I}^{2}=67 \%, \mathrm{P}<0.01\right)$ at 6 months post intervention (Figure 3).

The improvements in the 1-hour pad weight test results also revealed the curative effect of laser therapy. The changes at 1, 3, and 12 months were -5.59 (95\% CI: -6.93--4.25; I $\left.\mathrm{I}^{2}=85 \%, \mathrm{P}<0.01\right),-4.96$ (95\% CI: $-6.73-$ $-3.20 ; \mathrm{I}^{2}=60 \%, \mathrm{P}=0.08$ ), and -5.82 (95\% CI: $-6.77--4.87$; $\left.\mathrm{I}^{2}=58 \%, \mathrm{P}<0.09\right)$, respectively.

The PISQ-12 score improved from baseline to postintervention for SUI was 5.39 (95\% CI: $1.20-9.58 ; \mathrm{I}^{2}=96 \%$, $\mathrm{P}<0.01)$

Almost every indicator displayed significant heterogeneity among these data. It is worth noting that the one-arm meta-analysis was less stable compared the two-arm meta-analysis, contributing to the high level of heterogeneity observed in this study.

\section{Subgroup analysis}

Subgroup analysis was performed to identify the sources of heterogeneity. Geographic region, laser type, UI type, severity, age, and BMI were evaluated as possible covariates. Our findings led to the identification of UI type as the main source of heterogeneity, followed by the mean age.

The change in ICIQ-SF score at 1 month after intervention was -7.35 (95\% CI: $-7.69-7.01 ; \mathrm{I}^{2}=59 \%$, 
Table 1 Baseline characteristics of selected studies

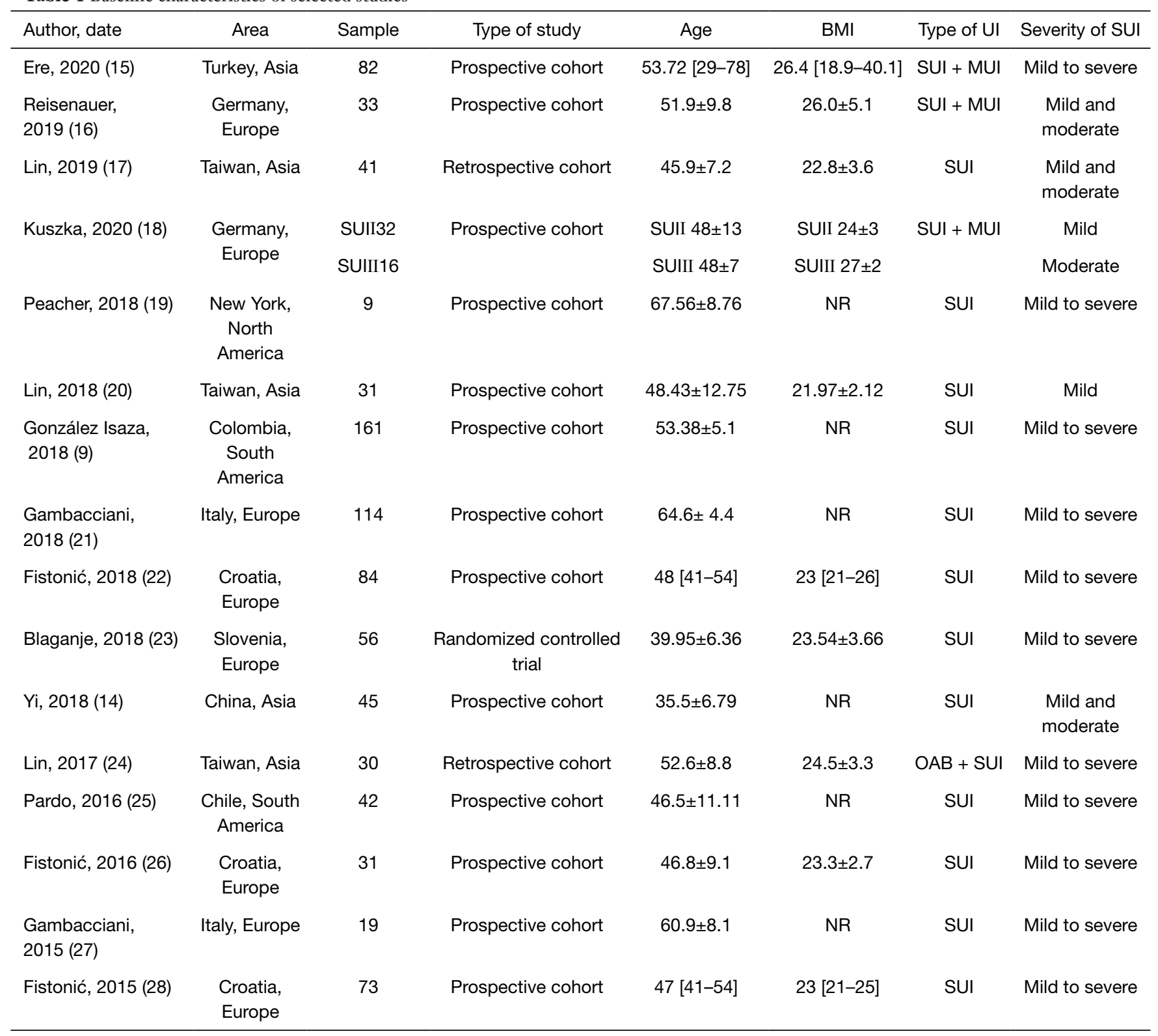

Values are expressed as mean \pm standard deviation or median [interquartile range]. BMI, body mass index; UI, urinary incontinence; SUI, stress urinary incontinence; MUI, mixed urinary incontinence; NR, not reported.

$\mathrm{P}=0.04$ ) for SUI of all degrees of severity (from mild to very severe), and -4.15 (95\% CI: $-4.98--3.31 ; \mathrm{I}^{2}=0 \%, \mathrm{P}=0.38$ ) for SUI of only one degree (mild or moderate). At 3 months after intervention, 3 sessions of laser treatments yielded a change in ICIQ-SF score of -6.06 (95\% CI: -6.45--6.67; $\left.\mathrm{I}^{2}=0 \%, \mathrm{P}=0.42\right)$, and $1-2$ sessions yielded a change in score of -3.75 (95\% CI: $\left.-4.48--2.91 ; \mathrm{I}^{2}=0 \%, \mathrm{P}=0.44\right)$. The change in ICIQ-SF score at 6 months after intervention was -6.73 (95\% CI: $-7.55--5.90 ; \mathrm{I}^{2}=0 \%, \mathrm{P}=0.57$ ) for SUI of all degrees of severity (from mild to very severe), -4.20 (95\% CI: $-4.95--3.45 ; \mathrm{I}^{2}=20 \%, \mathrm{P}=0.29$ ) for SUI for only one degree (mild or moderate), and -5.39 (95\% CI: $-5.78-$ $\left.-5.00 ; \mathrm{I}^{2}=28 \%, \mathrm{P}=0.25\right)$ for patients with combined SUI and MUI or GSM (Figure 4).

The change in 1-hour pad test score at 1 month after intervention was -6.40 (95\% CI: -6.66--6.14; $\mathrm{I}^{2}=14 \%$, 
Table 2 Summary of laser therapies and treatment duration for the selected studies

\begin{tabular}{|c|c|c|c|c|}
\hline Author, date & Laser type & Therapy mode & $\begin{array}{l}\text { Treatment } \\
\text { sessions }\end{array}$ & $\begin{array}{l}\text { Follow-up time } \\
\text { (months) }\end{array}$ \\
\hline Ere, 2020 (15) & Erbium:YAG & $7 \mathrm{~mm}$ spot-size, $10.0 \mathrm{~J} / \mathrm{cm}^{2}, 250 \mathrm{~ms}, 1.6 \mathrm{~Hz}$ & 1 & 6 \\
\hline Lin, 2019 (17) & Erbium:YAG & Three phases: $10.0 \mathrm{~J} / \mathrm{cm}^{2}, 1.6 \mathrm{~Hz}$ & 3 & 6 \\
\hline Kuszka, 2020 (18) & Erbium:YAG & $\begin{array}{l}\text { First phase: } 7 \mathrm{~mm} \text { spot-size, } 6 \mathrm{~J} / \mathrm{cm}^{2}, 1.6 \mathrm{~Hz} \text {; second phase: } 7 \mathrm{~mm} \\
\text { spot-size, } 3 \mathrm{~J} / \mathrm{cm}^{2}, 1.6 \mathrm{~Hz} \text {; third phase: } 10 \mathrm{~J} / \mathrm{cm}^{2}, 1.6 \mathrm{~Hz}\end{array}$ & 5 & $2,4,10,28$ \\
\hline Peacher, 2018 (19) & Both & $\begin{array}{l}\text { First phase: } 3 \mathrm{~J} / \mathrm{cm}^{2}, 7 \mathrm{~mm} \text { spot-size, } 6 \mathrm{~J} / \mathrm{cm} \text {; second phasecm: } \\
3.7 \mathrm{~mm} \text { spot-size, } 10 \mathrm{~J} / \mathrm{cm}^{2} ; \mathrm{CO}_{2} \text { laser: dot power } 30 \text { watt }\end{array}$ & 1 & 2 \\
\hline Lin, 2018 (20) & $\mathrm{CO}_{2}$ laser & NP & 4 & $12,24,36$ \\
\hline $\begin{array}{l}\text { González Isaza, } \\
2018 \text { (9) }\end{array}$ & Erbium:YAG & $7 \mathrm{~mm}$ spot-size, $6 \mathrm{~J} / \mathrm{cm}^{2}, 1.6 \mathrm{~Hz}$ & 3 & $1,3,6,12,18,24$ \\
\hline Fistonić, 2018 (22) & Erbium:YAG & $10 \mathrm{~J} / \mathrm{cm}^{2}, 7 \mathrm{~mm}$ spot size & 1 & 3 \\
\hline Blaganje, 2018 (23) & Erbium:YAG & $\begin{array}{l}\text { First and second phase: } 7 \mathrm{~mm} \text { spot-size, } 10 \mathrm{~J} / \mathrm{cm}^{2} \text { (upper part of } \\
\text { the vagina) and } 6 \mathrm{~J} / \mathrm{cm}^{2} \text { (lower part of the vagina), } 1.6 \mathrm{~Hz} \text {; third } \\
\text { phase: } 7 \mathrm{~mm} \text { spot-size, } 2.5 \mathrm{~J} / \mathrm{cm}^{2}, 1.6 \mathrm{~Hz}\end{array}$ & 3 & 1 \\
\hline Yi, 2018 (14) & Erbium:YAG & NP & 2 & $1,3,12$ \\
\hline Lin, 2017 (24) & Erbium:YAG & $6 \mathrm{~J} / \mathrm{cm}^{2}, 1.6 \mathrm{~Hz}$ & 2 & $3-6$ \\
\hline Pardo, 2016 (25) & Erbium:YAG & $\begin{array}{l}\text { First phase: } 3 \mathrm{~J} / \mathrm{cm}^{2} \text {, second phase: } 6 \mathrm{~cm}^{2} \text {, third phase: } 10 \mathrm{~cm}^{2} \text {. All } \\
\text { for } 1.6 \mathrm{~Hz}\end{array}$ & 1 & $1,2,6$ \\
\hline
\end{tabular}

Both, one group of Erbium:YAG, another group of $\mathrm{CO}_{2}$ laser; treatment sessions at an interval of 4 weeks. NR, not reported.

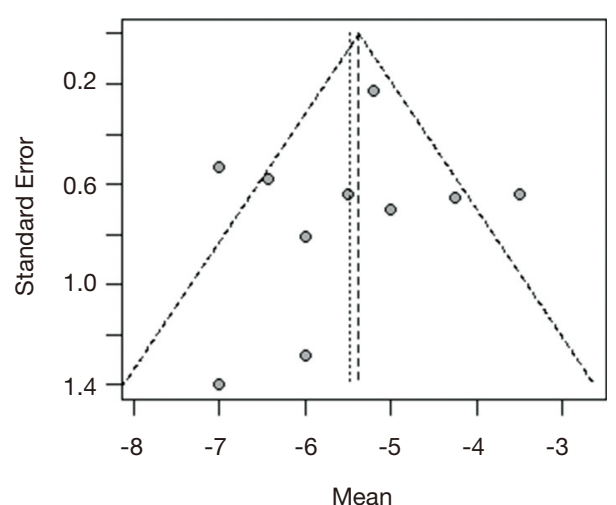

Figure 2 Funnel plot of ICIQ-SF at 6 months after intervention.
$\mathrm{P}=0.31)$. for SUI of moderate and above severity. At 3 months after intervention, the change in score for SUI with a severity greater than mild was -6.12 (95\% CI: -7.93$\left.-4.30 ; \mathrm{I}^{2}=0 \%, \mathrm{P}=0.71\right)$.

\section{Adverse events}

Adverse effects were reported in 6 of the 15 included trials (Table 3), with vaginal discharge observed in 4 of these studies. Blaganje et al. reported 49/56 patients, other studies only had less than 5 patients (23).

Furthermore, 2 studies reported de novo urgency in 2 patients, while weak pain was observed in 6 patients in another trial. Lin et al. reported vaginal itching in 3 patients, while increased vaginal discharge was observed in 3 subjects. Vulva discoloration was exhibited by 5 patients, while 


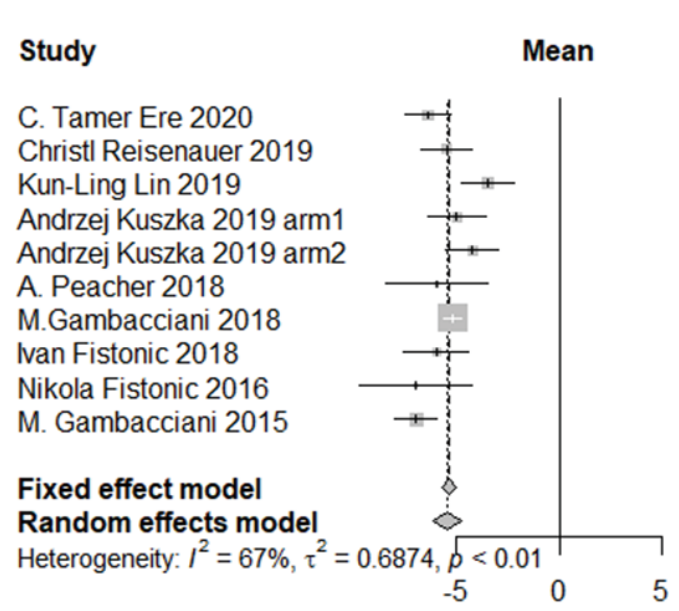

\begin{tabular}{|c|c|c|c|}
\hline MRAW & $95 \%-\mathrm{Cl}$ & $\begin{array}{r}\text { Weight } \\
\text { (fixed) }\end{array}$ & $\begin{array}{l}\text { Weight } \\
\text { random) }\end{array}$ \\
\hline-6.43 & {$[-7.57 ;-5.29]$} & $7.7 \%$ & $11.5 \%$ \\
\hline-5.50 & {$[-6.75 ;-4.25]$} & $6.4 \%$ & $10.8 \%$ \\
\hline-3.50 & {$[-4.75 ;-2.25]$} & $6.4 \%$ & $10.8 \%$ \\
\hline-5.00 & {$[-6.38 ;-3.62]$} & $5.3 \%$ & $10.0 \%$ \\
\hline-4.25 & {$[-5.53 ;-2.97]$} & $6.1 \%$ & $10.6 \%$ \\
\hline-6.00 & {$[-8.51 ;-3.49]$} & $1.6 \%$ & $5.1 \%$ \\
\hline-5.20 & {$[-5.64 ;-4.76]$} & $51.6 \%$ & $16.0 \%$ \\
\hline-6.00 & {$[-7.58 ;-4.42]$} & $4.0 \%$ & $8.8 \%$ \\
\hline-7.00 & {$[-9.75 ;-4.25]$} & $1.3 \%$ & $4.4 \%$ \\
\hline-7.00 & {$[-8.04 ;-5.96]$} & $9.4 \%$ & $12.2 \%$ \\
\hline $\begin{array}{l}-5.37 \\
-5.48\end{array}$ & $\begin{array}{l}{[-5.69 ;-5.06} \\
{[-6.15 ;-4.81}\end{array}$ & $100.0 \%$ & $100.0 \%$ \\
\hline
\end{tabular}

Figure 3 Forest plot showing the changes in the median ICIQ-SF scores between baseline and 6 months post intervention. The size of each square is proportional to the study's weight. Horizontal lines indicate $95 \%$ CI. Diamonds indicate pooled incidence rate with its corresponding $95 \% \mathrm{CI}$.

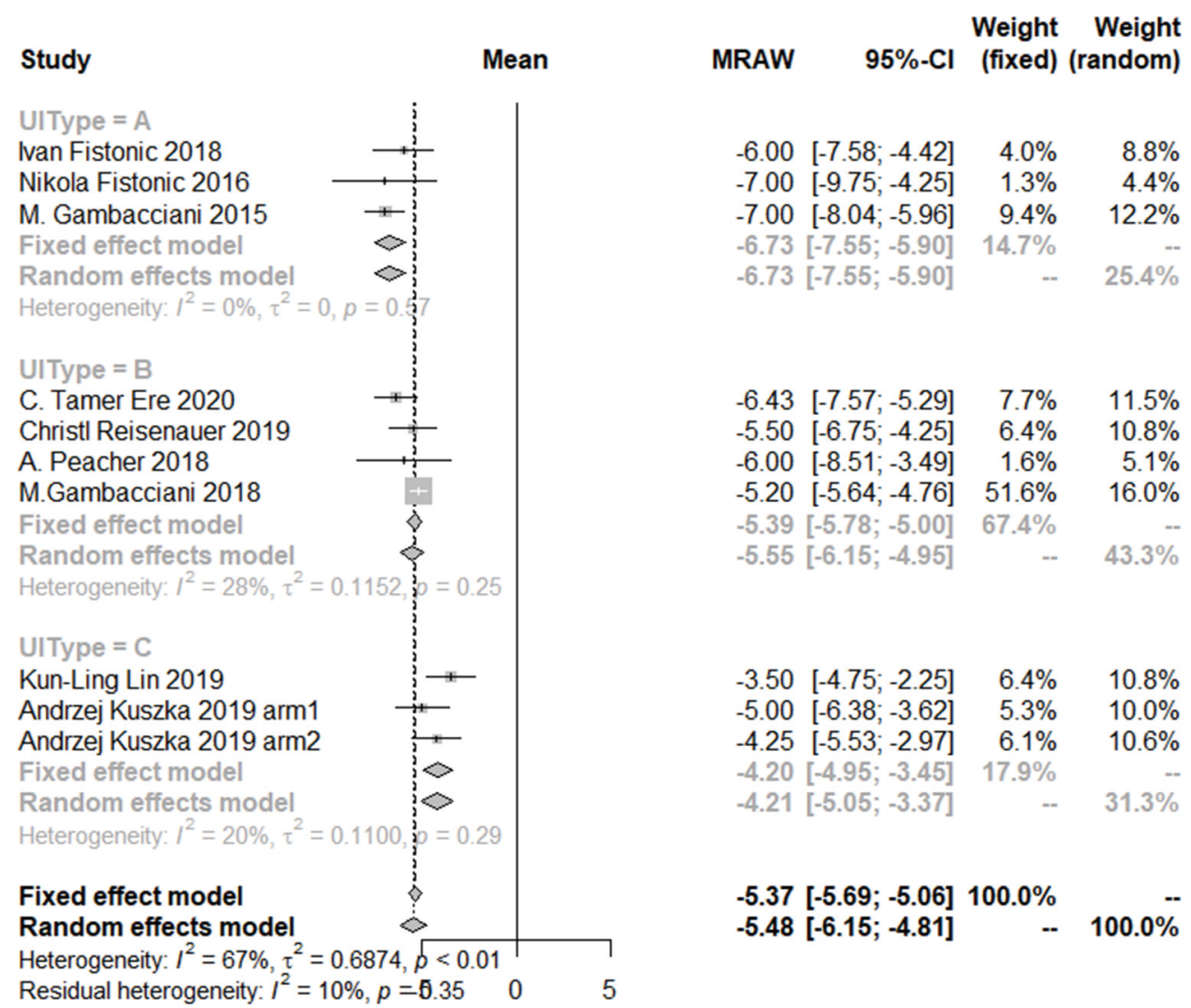

Figure 4 Forest plot showing changes in the median ICIQ-SF scores for the different types of urinary incontinence between baseline and 6 months post intervention. 
Table 3 Summary of the adverse reactions reported in the selected studies

\begin{tabular}{|c|c|}
\hline Author, date & Adverse reactions \\
\hline Reisenauer, 2019 (16) & 10 for vaginal discharge, spotting, burning sensation and/ or irritation for some days up to 4 weeks \\
\hline Lin, 2019 (17) & Not found \\
\hline Kuszka, 2020 (18) & 6 for weak pain, 1 for vaginal discharge \\
\hline González Isaza, 2018 (9) & Not found \\
\hline Gambacciani, 2018 (21) & Not found \\
\hline Fistonić, 2018 (22) & NR \\
\hline Blaganje, 2018 (23) & 49 for vaginal discharge, 2 for de novo urgency, 1 for increased vaginal dryness \\
\hline Pardo, 2016 (25) & Not found \\
\hline Fistonić, 2016 (26) & Not found \\
\hline Gambacciani, 2015 (27) & 1 for burning \\
\hline Fistonić, 2015 (28) & 1 for de novo urgency \\
\hline
\end{tabular}

The digits represent the number of patients. NR, not reported.

abnormal vaginal bleeding was reported in 2 patients. These adverse reactions healed without medical intervention or resolved within a few days after treatment. Essentially, most patients reported a slight burning sensation during the treatment. No significant adverse reactions were observed.

\section{Discussion}

Our findings clearly demonstrate the success of laser therapy in treating SUI, despite its relative newness as a form of therapy. The reviewed studies were predominantly published in 2015, with some published as long as a decade ago. The many approaches to SUI treatment, such as behavioral therapy, pelvic floor muscle exercises, electric stimulation, and pharmacological treatment, have inherent limitations (8). Nevertheless, the Erbium and low-energy $\mathrm{CO}_{2}$ lasers are strongly absorbed in water and increase the tissue temperature to $60-70{ }^{\circ} \mathrm{C}$ without causing tissue removal. This leads to collagen denaturation, remodeling, and neogenesis without ablation or irreversible tissue damage $(29,30)$. Laser therapy is a safe, effective, and minimally invasive therapeutic option for SUI that has a high compliance rate; it can also be applied to other UI types. In the vast majority of studies, the complications reported for laser therapy have been minor, transient, and extremely low in frequency, highlighting laser therapy as safe and well tolerated. Laser can induce collagen contraction, new collagen formation, vascularization, growth factor infiltration, restore elasticity, and lead to the thickening of the vaginal epithelium (31). As evidenced in this investigation, most of the studies were conducted with the Erbium YAG Laser using SMOOTH® Technology. This parameter setting was selected to avoid laser penetration into underlying tissues and organs, while only producing thermal and non-ablation effects, to achieve the safest and most efficacious therapeutic regimen (15).

ICIQ-SF and 1-hour pad tests demonstrated a statistically significant treatment effect in SUI improvement. Our results showed that the ICIQ-SF maximum improvement occurred at 6 months, with a maximum improvement in the 1-hour pad test observed at 12 months. This illustrates that laser treatment can also achieve enhanced long-term efficacy. However, data on long-term efficacy were limited, with only one study reporting follow-up durations of 12,24 , and 36 months, and another conducting follow-up visits at 12, 18 , and 24 months $(9,21)$. Gambacciani et al. treated 114 patients and suggested that the improvement of ICIQ-SF scores diminished continuously at 18 and 24 months (21). 
González Isaza et al. proposed that the curative effects of the $\mathrm{CO}_{2}$ laser were maintained after 36 months of observation without any need for further reintervention (9). Evidence that Er: YAG laser yielded similar improvement rates in the 1-hour pad test, ISIQ-SF, and OABSS at 12 months compared with sling procedures (TOT-TVT) has also been reported (32). Therefore, further studies with robust statistical analyses are required to establish the exact longterm effect of laser treatment.

From the subgroup analysis, we identified the scores that indicated enhanced improvement in patient characteristics which has all degree severity (from mild to very severe) than which has only one or two types of UI. This may be related to a lower baseline ICIQ-SF and 1-hour pad test in milder SUI cases, limiting the scope for improvement. SUI patients also evidently benefited more from laser treatment than MUI or patients with other UI types $(9,15,16,18,21,24,27)$. Statistical analyses of SUI and patients with other UI types or symptoms could not be separately performed, due to the limited amount of clinical information.

Kuszka et al. presented strong evidence that demonstrated a strong dependency on initial incontinence severity in the success of laser therapy (18). Patients were divided into different groups, based on the degrees of SUI and laser treatment was found to have almost no effect on severe SUI (total incontinence at all times). We therefore selected mild and moderate patients for two arms to underway metaanalysis.

The subgroup analysis of ICIQ-SF at 3 months revealed that 3 sessions of treatment achieved a greater improvement compared to the results from 1 or 2 sessions. While half of the selected studies showed that a more appropriate protocol would comprise three or more laser treatment sessions at monthly intervals, a trend in improvement was not reported in trials when the number of sessions exceeded three $(9,17-19,21,22,24,27)$. Fistonic et al. suggested that only a small improvement in the ICIQSF score was achieved after a 1-month follow-up (26). Therefore, some articles indicated a necessity for annual maintenance treatments for the effects of laser treatment to be sustained at a satisfactory level $(15-17,19,21-27)$. Further modification of the treatment plan is needed to optimise and sustain the efficacy of laser therapy.

Apart from the ICIQ-SF and 1-hour pad test, changes in PISQ-12 can also reflect the efficacy of laser therapy in treating SUIs and improving the quality of women's lives, despite the sources of heterogeneity not being identified.
Several studies proposed that age, menopause, and BMI can be used as predictors of laser treatment efficacy for SUIs $(15,18,22,28)$. Despite the suggestion that patients with a lower age or BMI displayed better improvement in UI symptom relief, with less retreatment and longer improvement duration, statistically significant effects of BMI were not observed in our subgroup analysis (28). This may be attributable to complex processes involving multiple factors, such as the use of local estrogen (estriol) before treatment in postmenopausal women, which can reduce the risk of menopause (25). This finding suggests that pretreatment with local estrogen is a viable means of treating late-postmenopausal women, and that weight management should be promoted to achieve better outcomes (15).

To our knowledge, this is the first meta-analysis of the clinical efficacy and safety of lasers in SUI treatment. Moreover, the subjects in the studies included were from various countries; thus, the sample was widely representative. There are some limitations to the present study that should be addressed. Only one randomized control trial (RCT) (23) was identified, and the vast majority of the remaining cohort studies undertook short-term follow-ups without control groups. Also, small study populations limited the data integrity of the study results. More randomized control trials should be carried out to eliminate the influence of a placebo effect. Furthermore, many patients were lost to follow-up due to the rapid resolution of symptoms after one or two treatments, thereby decreasing their motivation for continued study participation (26). From this perspective, retention measures need to be established and implemented to retain patient participation $(17,28)$. Fistonić et al. assumed no treatment effect for all patients who were lost to follow-up through a sensitivity analysis and were still able to achieve a statistically significant curative effect (28). The study was designed as a single-arm study, so we could not compare laser therapy to other therapeutic methods. Moreover, the inconsistency in the parameters used across the different studies, combined with potential confounding factors, mean that further research is necessary to confirm the accuracy of our findings. Considering the lack of studies of consistent RCT data for lasers in SUI, further trials are warranted. In addition, there is no unified standard of the parameters for laser therapy, effectiveness and safety in particular should be interpreted with caution.

\section{Conclusions}

Vaginal laser therapy can improve the symptoms of 
women with SUI. It appears to be an effective, safe, and minimally invasive treatment option for SUI that can be well tolerated. Our study demonstrated that both $\mathrm{CO}_{2}$ and Erbium: YAG laser therapy could be used to successfully treat SUI and improve the quality of women's lives (20). In cases of severe SUI, surgery can be avoided or postponed by using laser therapy. Further studies are necessary to research the long-term results of vaginal laser therapy in comparison to other treatments, including surgery or muscle function exercise of SUI.

\section{Acknowledgments}

Funding: This work was supported by financial grants from the National Natural Science Foundation of China (No. 30873268).

\section{Footnote}

Reporting Checklist: The authors have completed the PRISMA reporting checklist. Available at http://dx.doi. org/10.21037/apm-20-1440

Conflicts of Interest: All authors have completed the ICMJE uniform disclosure form (available at http://dx.doi. org/10.21037/apm-20-1440). The authors have no conflicts of interest to declare.

Ethical Statement: The authors are accountable for all aspects of the work in ensuring that questions related to the accuracy or integrity of any part of the work are appropriately investigated and resolved.

Open Access Statement: This is an Open Access article distributed in accordance with the Creative Commons Attribution-NonCommercial-NoDerivs 4.0 International License (CC BY-NC-ND 4.0), which permits the noncommercial replication and distribution of the article with the strict proviso that no changes or edits are made and the original work is properly cited (including links to both the formal publication through the relevant DOI and the license). See: https://creativecommons.org/licenses/by-nc-nd/4.0/.

\section{References}

1. Haylen BT, de Ridder D, Freeman RM, et al. An International Urogynecological Association (IUGA)/ International Continence Society (ICS) joint report on the terminology for female pelvic floor dysfunction. Int Urogynecol J 2010;21:5-26.

2. Luber KM. The definition, prevalence, and risk factors for stress urinary incontinence. Rev Urol 2004;6:S3.

3. Ghoniem G, Stanford E, Kenton K, et al. Evaluation and outcome measures in the treatment of female urinary stress incontinence: International Urogynecological Association (IUGA) guidelines for research and clinical practice. Int Urogynecol J Pelvic Floor Dysfunct 2008;19:5-33.

4. Abrams P, Andersson KE, Birder L, et al. Fourth International Consultation on Incontinence Recommendations of the International Scientific Committee: Evaluation and treatment of urinary incontinence, pelvic organ prolapse, and fecal incontinence. Neurourol Urodyn 2010;29:213-40.

5. Sturdee DW, Panay N. International Menopause Society Writing Group. Recommendations for the management of postmenopausal vaginal atrophy Climacteric 2010;13:509-22.

6. Ronconi L, Galli M. MonaLisa Touch ${ }^{\mathrm{TM}}$ : the latest frontier in the treatment of vaginal atrophy. DEKA Ed Scientific Series 2012;2.

7. Dumoulin C, Cacciari LP, Hay-Smith EJC. Pelvic floor muscle training versus no treatment, or inactive control treatments, for urinary incontinence in women. Cochrane Database Syst Rev 2010;(1):CD005654.

8. Long RM, Giri S, Flood H. Current concepts in female stress urinary incontinence. Surgeon 2008;6:366-72.

9. González Isaza P, Jaguszewska K, Cardona JL, et al. Long-term effect of thermoablative fractional $\mathrm{CO}_{2}$ laser treatment as a novel approach to urinary incontinence management in women with genitourinary syndrome of menopause. Int Urogynecol J 2018;29:211-5.

10. Schimpf MO, Rahn DD, Wheeler TL, et al. Sling surgery for stress urinary incontinence in women: a systematic review and metaanalysis. Am J Obstet Gynecol 2014;211:71.e1-e27.

11. Espuña Pons M, Rebollo PA, Puig MC. Validation of the Spanish version of the International Consultation on Incontinence Questionnaire-Short Form. A questionnaire for assessing the urinary Incontinence. Medicina Clinica 2004;122:288-92.

12. Rogers RG, Coates KW, Kammerer-Doak D, et al. A short form of the pelvic organ prolapse/urinary incontinence sexual questionnaire (PISQ-12). Int Urogynecol J Pelvic Floor Dysfunct 2003;14:164-8.

13. Krhut J, Zachoval R, Smith PP, et al. Pad weight testing in the evaluation of urinary incontinence. Neurourol Urodyn 
2014;33:507-10.

14. Yi W, Minjian C, Yong S. Observation and feasibility analysis of short-term curative effect of 2940nm 3D lattice erbium laser for vaginal relaxation syndrome. Heilongjiang Traditional Chinese Medicine 2018;47:56-8.

15. Erel CT, Inan D, Mut A. Predictive factors for the efficacy of Er:YAG laser treatment of urinary incontinence.

Maturitas 2020;132:1-6.

16. Reisenauer C, Hartlieb S, Schoenfisch B, et al. Vaginal therapy of mild and moderate stress urinary incontinence using Er:YAG laser: a real treatment option. Arch Gynecol Obstet 2019;300:1645-50.

17. Lin KL, Chou SH, Long CY. Effect of Er:YAG Laser for Women with Stress Urinary Incontinence. Biomed Res Int 2019;2019:7915813.

18. Kuszka A, Gamper M, Walser C, et al. Erbium:YAG laser treatment of female stress urinary incontinence: midterm data. Int Urogynecol J 2020;31:1859-66.

19. Peacher A, Andiman S, Isola H, et al. The use of fractional $\mathrm{CO}_{2}$ laser for improvement of stress urinary incontinence: A pilot study. Female Pelvic Med Reconstructive Surg 2018;2:S81-S2.

20. Lin HY, Tsai HW, Tsui KH, et al. The short-term outcome of laser in the management of female pelvic floor disorders: Focus on stress urine incontinence and sexual dysfunction. Taiwan J Obstet Gynecol 2018;57:825-9.

21. Gambacciani M, Levancini M, Russo E, et al. Longterm effects of vaginal erbium laser in the treatment of genitourinary syndrome of menopause. Climacteric 2018;21:148-52.

22. Fistonić I, Fistonic N. Baseline ICIQ-UI score, body mass index, age, average birth weight, and perineometry duration as promising predictors of the short-term efficacy of Er:YAG laser treatment in stress urinary incontinent women: A prospective cohort study. Lasers Surg Med 2018. [Epub ahead of print].

23. Blaganje M, Scepanovic D, Zgur L, et al. Non-ablative Er:YAG laser therapy effect on stress urinary incontinence related to quality of life and sexual function: A randomized controlled trial. Eur J Obstet Gynecol Reprod Biol 2018;224:153-8.

24. Lin YH, Hsieh WC, Huang L, et al. Effect of nonablative laser treatment on overactive bladder symptoms, urinary incontinence and sexual function in women with urodynamic stress incontinence. Taiwan J Obstet Gynecol 2017;56:815-20.

25. Pardo JI, Sola VR, Morales AA. Treatment of female stress urinary incontinence with Erbium-YAG laser in non-ablative mode. Eur J Obstet Gynecol Reprod Biol 2016;204:1-4.

26. Fistonić N, Fistonic I, Gustek SF, et al. Minimally invasive, non-ablative Er:YAG laser treatment of stress urinary incontinence in women--a pilot study. Lasers Med Sci 2016;31:635-43.

27. Gambacciani M, Levancini M, Cervigni M. Vaginal erbium laser: the second-generation thermotherapy for the genitourinary syndrome of menopause. Climacteric 2015;18:757-63.

28. Fistonić N, Fistonic I, Lukanovic A, et al. First assessment of short-term efficacy of Er:YAG laser treatment on stress urinary incontinence in women: prospective cohort study. Climacteric 2015;18 Suppl 1:37-42.

29. Gambacciani M, Palacios S. Laser therapy for the restoration of vaginal function. Maturitas 2017;99:10-5.

30. Tadir Y, Gaspar A, Lev-Sagie A, et al. Light and energy based therapeutics for genitourinary syndrome of menopause: consensus and controversies. Lasers Surg Med 2017;49:137-59.

31. Salvatore S, Leone Roberti Maggiore U, Athanasiou S, et al. Histological study on the effects of microablative fractional $\mathrm{CO}_{2}$ laser on atrophic vaginal tissue: an ex vivo study. Menopause 2015;22:845-9.

32. Okui N. Comparison between erbium-doped yttrium aluminum garnet laser therapy and sling procedures in the treatment of stress and mixed urinary incontinence. World J Urol 2019;37:885-9.
Cite this article as: Wang Y, Wang C, Song F, Zhou Y, Wang Y. Safety and efficacy of vaginal laser therapy for stress urinary incontinence: a meta-analysis. Ann Palliat Med 2021;10(3):27362746. doi: 10.21037/apm-20-1440 